\title{
Educación y literatura: exploraciones de una relación amorosa e in-evaluable 1
}

\author{
Facundo Giuliano \\ Doctor en Ciencias de la Educación \\ Universidad de Buenos Aires \\ https://orcid.org/0000-0003-3404-1612 \\ giulianofacundo@gmail.com \\ Grisel Serratore \\ Profesora y Licenciada en Filosofía \\ Universidad de Buenos Aires \\ http://orcid.org/0000-0001-7333-6347 \\ griselserratore@hotmail.com \\ Luisina Zanetti \\ Profesora y Licenciada en Ciencias de la Educación \\ Universidad Nacional de Córdoba, Argentina. \\ https://orcid.org/0000-0002-1203-0827 \\ luisij.zanetti@gmail.com
}

Estamos

$(\ldots)$

con aire de tenaz porfía

y toda rebelión cabe

en el puño que crispamos

para defender del viento

el único bastión erguido

en el desierto que habitamos.

Silvia N. Barei, De humana condición

\section{Resumen}

El presente ensayo convida algunas exploraciones de la relación entre educación y literatura, abrazada en su impronta filosófica e in-evaluable. Su composición ahorra en sistematicidad lo que no escatima en reflexividad, por lo cual no se imponen lógicas introductorias o conclusivas con pretensiones totalizantes. Se revuelve entre fuentes en busca de detritos que alimenten dicha relación descuidada, generalmente, por las manías que dejan a la literatura en los cercos que el poder disciplinario le impone. Así, se asoma la idea de una educación literaria que libera el deseo, entre enigmas y lecturas del mundo, en contraposición a todo afán de domesticación.

\footnotetext{
1 Procedencia del artículo: Este artículo se inscribe en el proyecto de investigación FiloCyT "Educación, filosofía y psicoanálisis: la potencia de un anudamiento indisciplinario frente al capitalismo contemporáneo", dirigido por Facundo Giuliano y con sede en el Instituto de Investigaciones en Ciencias de la Educación (UBA).
} 
En su frente se ciñe un arte y una política del educar que inspiran formas de resistencia, al tiempo que habitan la selva semiótica en la que se juega una enseñanza de escape y superstición. Finalmente, las pronunciaciones insinúan una poética del cuidado que desenlaza en una pregunta vital por el estudiar.

Palabras clave: educación literaria; evaluación; filosofía; pedagogía; política.

\section{Education and literature: explorations of a loving and un- evaluable relationship}

\section{Abstract}

This essay invites some explorations of the relationship between education and literature, embraced in its philosophical and un-evaluable stamp. Its composition saves on systematization that does not skimp on reflexivity, which is why introductory or conclusive logics with totalizing claims are not imposed. He rummages among sources in search of debris that feed this relationship generally neglected by the manias that leave literature in the fences that the disciplinary power imposes on it. This is how the idea of a literary education that frees desire appears, amidst enigmas and readings of the world, as opposed to any desire for domestication. In his forehead an art and a policy of educating is girded that inspires forms of resistance, while inhabiting the semiotic jungle where a teaching of escape and superstition is played. Finally, the pronunciations hint at a poetics of care that unravels into a vital question for studying.

Keywords: evaluation; literary education; pedagogy; politics; philosophy.

Recibido: 20 de diciembre del 2020. Aprobado: 15 de febrero del 2021

Artículo de reflexión https://doi.org/10.25100/poligramas.v0i52.11280

¿Cómo citar este artículo en MLH? - How to quote this article in MLA?

Giuliano, Facundo; Grisel Serratore y Luisina Zanetti. "Educación y literatura: exploraciones de una relación amorosa e in-evaluable" Poligramas 52 (2021): e,2211280. Web. Fecha de acceso (día, mes en mayúscula y abreviado, y año) 


\section{Obertura: una educación (o una enseñanza) menos literal y más literaria}

Se sabe que la luz del sol, con paulatina insistencia, si no se toman los cuidados pertinentes, va quemando las páginas de los libros hasta que adquieren un tono opaco amarillo que se resiste a los resaltadores fluorescentes y dificulta las andanzas del grafito. El iluminado paso del tiempo pesa en las hojas que apenas ofrecen sus huellas de imprenta y ya no se prestan con gran entusiasmo al gesto de estudiosos y profetas. Algo que podría recordarnos a la llustración, que, en su intento de acabar con las tinieblas, pensó en superar la infancia como clave y desembocó en la respiración mortificante de una mayoría de edad sin aire, sin juego, sin tiempo.

El mundo y sus episodios convulsivos de agonía parecen olvidar con frecuencia las ficciones sobre las que se afincan sus desgracias, y sus incómodos extremos se disputan entre sí lo urgente, lo real, lo literal y lo contingente. Un desfiladero de medios lo acreditan, mientras las escuelas tiemblan y sus docencias no interrumpen la extenuación producida por un extraño complejo de heroísmo. En este repetitivo y cada vez más exasperante contexto, ¿qué vuelco podría darla enseñanza?, ¿cuál será su forma de liberarse con el mismo pueblo que, al moverse, alertó de sus cadenas?, ¿dónde comenzaría la acción colectiva de un movimiento docenteestudiantil en la trama comunal de una historia todavía por escribirse?

A comienzos de la década de 1930, Pedro Henríquez Ureña hablaba de una orientación literaria como una de las condiciones de la docencia y en esa fórmula compendiaba "todo el secreto de la enseñanza literaria, tanto en la escuela elemental como en la superior" (3). Sin establecer niveles, esta condición de la enseñanza sería la que permitiría a cualquier docente distinguir entre la literatura que no escatima generosidad ni esfuerzo en convidar elementos de interpretación vital y la que solo "representa una habilidad para simular sentimientos o ideas, repitiendo fórmulas (...) para hacerse aplaudir" (Henríquez Ureña 3)². La diferencia podría visualizarse también en que esta última apela a perezas que se apoyan en la costumbre y se (di)secan en un mezquino lenguaje a veces jurídico, mientras la otra es capaz de germinar vagancias que crecen en la tierra fértil de la lectura y se enroscan en las conversaciones de los días. Se trata de una enseñanza que condensa siglos de vivencias y puede transmitirse a través

\footnotetext{
${ }^{2}$ De ahí que, entonces, resulte fundamental la diferencia entre literaturas que alimentan el juicio (y, por ende, la razón evaluadora) y las literaturas que ponen en juego diversos vitalismos como formas de lucha y re-existencia (Giuliano, Razón evaluadora).
} 
de gestos inscritos en el tiempo (un tiempo liberado del opresivo toma y daca, que suele ser la manifestación cabal de la pedagogía mercantil), a la vez que complementa (y no reduce) la poética que improvisa coplas leyendo el mundo y escribiendo el suelo.

Las docencias más rebeldes a la gramática no solo se declaran enemigas de las crueles clasificaciones que circulan por los manuales, también exploran los sentidos que vibran en una frase, tal vez porque "donde termina la gramática, comienza el arte" (Henríquez Ureña 5). Una pulsión herética habita en la enseñanza literaria que, por más que no se lo proponga, llega a tocar su idioma en una parte quizá cuantitativamente insignificante, pero cualitativamente enorme para los puristas defensores del statu quo. La conspiración se trama en un lenguaje del deseo que busca sin saber, pero con persistencia, inspirar el amor a la lectura donde el mundo, hecho de texto y barro, espera una voz junto a un par de manos que lo paseen por sus tonos altos y bajos, al tiempo que una interpretación se arriesga entre sus senderos de yuyales puntiagudos.

Una pizca de perseverancia y otra de atención pueden ser dos ingredientes de partida que luego se disuelven en la significación: bien parece un aprendizaje de infancia, cuando esta halla la fortuna de las canciones y los cuentos orales que son antesala del paso al gateo y el tanteo bípedo -a veces sedentario-, por esos raros objetos contundentes que resisten las desgracias de época y que conocemos con el nombre de libros. En algunos de ellos, si seguimos una pista sembrada por José Enrique Rodó, se juega toda iniciación literaria y no la mera instrucción: se trata, en suma, de una educación de la sensibilidad en la que se infunde el deseo y esa simpatía pedagógica que puede hacer traspasar los límites de su campo de acción, de la cátedra a la lectura popular.

Una educación literaria, entonces, necesita el aire de una docencia en rebeldía con las imposiciones y requerimientos que desigualan cualquier juego siempre a favor de los privilegiados. De aquí que a su enseñanza no le interese una literatura para pocos o una lectura clasificada en función de un prejuicio que no hace más que reificar algún tipo de subestimación. Quizá por este motivo Henríquez Ureña insta a la docencia a vencer el prejuicio de que ciertas textualidades puedan resultar "difíciles» para la infancia, acaso porque la dificultad reside en la complejidad de la experiencia de infancia -o la infancia de la experiencia- y no precisamente en el texto que puede ubicar nuestra experiencia en situación de infancia (Giuliano, Infancia y razón evaluadora). En esta línea, el pensador dominicano encuentra «deplorable» la literatura 
apellidada «infantil» porque en su fabricación (término que resalta por emparentarse con procedimientos mecánicos y seriados) pierde todo juego y empuje vital.

De modo que una lucha a nivel del lenguaje se traza en la docencia, más cuando se le desea "toda la valentía necesaria para combatir contra los múltiples efectos que los diarios (...) y la redacción de los anuncios de casas comerciales pueden ejercer" (Henríquez Ureña 12). Una forma de resistencia al ruidoso alarde triunfante, que no es más que el «abominable snobisma del que hablaba Rodó y que ciertos espíritus docentes podrían desterrar en favor de salvar "en el puerto abrigado y calmo de su piadosa memoria, nombres y obras que la injusticia o la indolencia de una época han condenado al olvido común" (568).

En este tipo de enseñanza, más literaria y menos literal, no tiene curso la docencia que se deja encandilar por el brillo monetario del renombre y la gloria, pues, en lo más hondo de sí, guarda ese tipo de amor que embellece el misterio: un afecto que alerta sobre la mezquindad existente en la brega por la notoriedad, en el sensualismo de la admiración y del aplauso.

\section{El deseo de aprender: entre enigmas y lecturas del mundo}

De las reiteradas preocupaciones que suelen ser motivo de conversación con colegas docentes, en torno a la enseñanza, hay una en particular que insiste con más afectación: la dificultad que los estudiantes presentan, en los llamados «procesos de aprendizaje», al no poder desprenderse de la palabra textual. Esa palabra que se enmarca en un lenguaje pragmático utilizado para completar consignas, para dirigirse en la clase o en los exámenes sobre 'lo visto', implica una lengua que -muchas veces- no consigue distanciarse de lo pronunciado por otros, o de lo que es lo mismo: de lo ya sabido. Es curioso notar en instancias de examen cómo se intenta resguardar la fidelidad textual que pocas veces permite disparar hacia nuevos rumbos de pensamientos y, en ocasiones, se pronuncia para quedarse en la certeza de haber dicho "lo que se tenía que decir", sin la chance de ir por sentidos otros que amenacen esa lealtad a la literalidad.

¿Será un miedo al decir por fuera de cualquier autoridad el que embarga los afectos de quien debería demostrar un «aprendizaje»? ¿O será que la enseñanza así planteada deja poco margen a las anotaciones que se ubican al costado del texto central exigido como futuro aprendizaje? ¿Qué sucedería si la enseñanza no se inscribiera en la lógica mercantil que reclama para sí, más tarde o más temprano, lo que dio? Tal vez no sería una necesidad aquella seguridad 
que se apoya fundamentalmente sobre lo ya dicho para calmar el temor a "desacertar» y el enigma de aprender se vería un poco más cuidado sin la obligación del salto al vacío, donde la única soga a la cual aferrarse es la propia voz o el intento de decir sin balbuceos, sin titubeos, sin vacilaciones o sin errores.

En un sentido quizá heideggeriano, lo que estamos siendo se encuentra perdido en "lo Uno» o en lo Impersonal, entre habladurías, entre las otras voces que dicen lo que hay que hacer o lo que se tiene que decir, y necesitará desandar esa cotidianidad en la que está sumergido como modo de acceder al aire de la superficie que singulariza su existencia. Puede que esto favorezca un pensar que transgrede cierto estado anquilosado hacia un sitio de mayor movimiento. De este modo, aprender como experiencia de «darse cuento» funciona como el pensar en el que se vuelve fundamental vivificar lo enunciado, preservando una capacidad inventiva asociada a la enseñanza que favorece la vivencia de lecturas del mundo como apertura de sentidos. La referencia a esa clase de experiencias podemos descubrirla en la lectura y escritura de quienes se dejan llevar por un imprevisible bocado de saber, que se saborea como delicia desconocida, que se disfruta como juego del deseo.

Ese podría ser el lugar de toda literatura que convide sentidos vitales a la propia vida, una manera de traducir aquellas figuras del misterio y de lo inexplicable que van horadando los cimientos de lo existente con la insuperable paciencia de la gota que perfora la roca. En otras palabras, es lo que ha marcado a escribientes como César Aira, que en alguna de sus infancias se vio buscando enigmas que no tuvieran respuesta, mientras otros buscaban desesperadamente certezas. Explorar lo desconocido como aventura imposible que acontece: no se trata de una nueva experiencia de conocimiento catalogable, sino de un deseo de lectura y escritura de un mundo que, sin embargo, se resiste a ser (d)escrito y leído. De allí parten las coordenadas de otro deseo que se instala, ese que se mueve por la pulsión de relectura y reescritura, aunque ya para entonces lo que se lee y lo que se escribe sea otro cantar.

Ese leer de alteridad, emparentado íntimamente con el enigmático aprender, se distancia de la actividad enciclopédica en la que se lee para acumular saberes repetibles. La lectura sistemática sin dislate, sagrada sin profanación, disciplinada sin transgresión, llega a convertir a cualquiera en ese personaje banal que algunos llaman el «hombre culto», el sujeto de todas las respuestas, el aburrido sabelotodo que reduce la formación a una educación repetitiva y acumulativa que se sitúa lejos de los puentes que nos desvían hacia 
otros sentidos del mundo hecho páginas. Así, se nos revelan formas de leer y -quizásaprender que surgen como opciones diferentes de vincularse con el saber, pero que, no obstante, encontramos entreveradas en las travesías de la formación.

Un deseo de aprender que nos sitúa en una lectura capaz de resignificar, se topa continuamente con la fuerza de lo establecido o del sentido clausurado que tiende a totalizar. Bajo esta especie de desdoblamiento propio de los procesos educativos es que se experimenta el desafío de aventurar nuevos caminos junto (y frente) a la suma de lo ya sabido, tal y como lo vislumbramos en algún relato en el que se narra una forma pícara de alteridad, dejando una y otra vez el que se es, el que ya se constituyó como tal, por iniciar otras búsquedas: "Hace años yo traté de librarme de él [de Borges] y pasé de las mitologías del arrabal a los juegos con el tiempo y con lo infinito, pero esos juegos son de Borges ahora y tendré que idear otras cosas. Así mi vida es una fuga y todo lo pierdo y todo es del olvido, o del otro" (Borges 808).

Esa alteridad que viene es capaz de enlazar literariamente el proceso educativo con lecturas del mundo, en la que también vivimos una suerte de fragmentación que invita a poner un pie en la tierra firme de lo dicho y empezar a tantear con el otro el barro incierto de una historia por comenzar. Principio del estar siendo que permite caminar manifestando otras formas de permanecer en pie y en búsqueda.

\section{Literatura: entre educación y domesticación}

En este tiempo de proliferación tecnológica, suele intentarse desesperadamente encontrar pistas que nos permitan pensar una diferencia entre educación y domesticación. Sin lugar a dudas, hay quienes reconocen entre ambas una unión tan intrínseca e íntima que se tornan sinónimos o partes de lo mismo. Allí, la escritura aparece como un cemento cómplice de la indestructible ligazón que no permite, siquiera, sospechar de la relación entre ambas. Es entonces cuando podríamos reconocer que algunas ideas cobran valor, por ejemplo, la de que la enseñanza sería mera alfabetización. O pensar en aquellos para quienes «vida» es solo si está escrita y las distinciones se le otorgan cuando cobra, o no, sentido.

La vida escrita, la cual debe ser la misma que merece ser examinada, cuenta con diversos elementos que la constituyen en tanto saber. La primacía de una historia le da una línea de continuidad; la intermitencia se la da el archivo; la interpretación, a esa línea, le da movimiento. La imitación, la copia y el mito de que no se pueda replicar le dan el valor que hace que sea 
aún más preciada. Te lo enseño, te lo muestro. Te muestro una parte. Esa vida se posee; algunos poseen esas líneas, otros no. La posesión es un rasgo distintivo, entonces, más bien que brille. Las letras doradas, entronadas, con decoraciones y ornamentos, son las que portan en libros los hombres de letras, dueños de su tiempo.

Peter Sloterdijk aporta otro elemento a la importancia que tiene la construcción de ese saber y es su relación con la selección la que denota un papel fundamental en la construcción de la lectura como potencia educadora, asegurando que en "ninguna época ha bastado solo con la domesticación educativa de los hombres" (68). Siguiendo esta idea, si la vida es la que está escrita, ciertamente, tras la selección, se demarcan otros ritmos y planes. No se trata solamente de un asunto de desarrollo cognitivo, quedan los retazos producto de la selección separados a un costado para ser vedados por inapropiados y otros que no pasan por el tamiz de la comprensión y son arrojados fuera. Así es que, a diferencia de los textos importantes, hay otros a los que les espera un plan sistemático de olvido.

Sin embargo, podríamos pensar que, en ese lugar de lo relegado o lo prohibido, se despliegan una suerte de otros elementos. Son guardados con sigiloso ingenio, permanecen ocultos y, en la espera, la mayor parte de sus existencias. Sobre-viven a la selección tras perder todo su valor, tal vez en formas de cartas clandestinas, en retazos de libros rotos, en palabras disfrazadas que no son portadas por hojas, sino como secretos guardados en los cuerpos. Tienen la potencia y su valor en lo urgente, que espera.

Esos retazos no llegan a atentar contra la literatura (canónica), ni le quitan su estatuto, aparentemente eso no es un riesgo ${ }^{3}$. Habitan en la marginalidad, sobre la base de «instrumentos literarios» o decididamente "pos-literarios», ideas que nos sitúan como mendigos y mendigas de las palabras.

Podríamos acordar que la vida tiene sentido y recordar que a veces tiene tanto sentido que puede incluso, entre las trenzas, dejar un mensaje. Al desanudar y entrelazar, con múltiples movimientos, pueden dibujarse los recovecos de un plan de escape. Con las formas que las manos de madres y abuelas van dejando en las cabelleras de las niñas, en silencio o murmurado un canto. Siempre ocultas en la aparente uniformidad, para quienes creen ver cabecitas iguales,

\footnotetext{
${ }^{3}$ Al decir de Sloterdijk: "las sociedades modernas sólo ya marginalmente pueden producir síntesis políticas y culturales sobre la base de instrumentos literarios (...). En modo alguno está acabada por ello la literatura" (2829).
} 
porque no todo es cuestión de darlo a conocer. Podríamos imaginar que se porta, como una prenda o como un regalo, el secreto que no se termina de develar.

Estas escenas evocadas, en el apuro por pensar una escapatoria a la domesticación y a la selección que la consiente, las podemos reivindicar en la prosa que nos propone María Teresa Andruetto. En la novela Lengua madre, cuenta las historias de tres mujeres que se entrelazan en una escritura que llega constantemente como un mensaje tardío. Estas mujeres, abuela, madre e hija, reviven entre sí las palabras, no sin el sufrimiento por los desquicios que implica dejarse atravesar y portarlas en sus cuerpos. Llevan en sí mismas un mensaje leve, como un reclamo inexpresivo pero insistente que pregunta ¿cómo es que la vida sigue? Sumergida en esas letras, la hija, protagonista de la historia, se esfuerza por no subrayar, por leer con la reserva de quien no quiere esa verdad, ni a favor ni en contra, de su vida, al tiempo que se narra una enseñanza que le dice "[quedan] en la boca, en las palabras, muchos restos de la tierra donde se crió, donde están unidas las tres para siempre" (Andruetto 61).

Difícil suponer que hay una sola idea de educación y que es la que responde al rebaño. ¿Cómo sería una educación que no busque una auto-regulación, que no se invista en el éxito? ¿Acaso la enseñanza no tiene un pulso propio cada vez que está siendo? Con escenas evocadas intentamos pensar en otras formas, más allá de la marginalidad que solo ubica a los sujetos en un plano. Pensamos en el deseo latente que alimenta los impulsos a escapar y a permanecer vivos, a sobre-vivir a los entornos que constantemente los disimulan y los borran.

Tal vez en las escenas cotidianas de resistencia habita la fuerza pedagógica de la literatura, es decir, de los pequeños relatos de los cuales somos portadores, pese a que se tornan inaudibles en algunos contextos e instituciones. Podríamos creer así en una filosofía que de ellos se despierta y que, al mismo paso, sienta las bases de otra escucha.

\section{En el frente: un arte y una política del educar}

Jean Meckert va al frente, pero no a ese lugar del aula que suele ser ocupado por docentes o por estudiantes que tienen alguna cita con la timidez y el coraje de exponer(se), sino al mismísimo campo de batalla durante la Segunda Guerra Mundial. No sabemos si se va allí con un puñado de ideas entre manos y vuelve con otra historia que narrar, o si es la imaginación a la que se aferra un joven que vive de sus 29 a 35 años sumido en una de las tragedias más grandes de la humanidad. Lo cierto es que a su regreso del frente publica Los golpes, una 
novela cuya primera versión fue escrita a sus 26 años, cuando ya sentía que no era un joven y que "hacía mucho tiempo que era un aprendiz de anciano" (Meckert 11).

¿Qué sensibilidad adquiere el pulso en su acto amoroso de abrazar la pluma luego de pasar por el frente? ¿Qué tan distante es el frente de batalla y el frente del aula cuando la vida se encuentra desnuda y expuesta ante las pocas palabras que somos capaces de pronunciar? ¿Será el mismo temblor el que recorre la mano cuando se toma el arma y se dibuja en el aire la maniobra contra el enemigo que el que aparece cuando se toma la tiza y se escribe en ese horizonte rectangular cuyo fondo puede ir del blanco al verde sin olvidarnos del negro? Las preguntas se asoman sin pretensiones de pronta respuesta.

Tal vez una diferencia se ubica en la lejanía que existe entre la lucha por que la educación implique una aventura para todo el mundo y la guerra que supone ganancia para unos pocos, pero siempre una desgracia para los pueblos. El arte de educar se hace de instantes que nunca son estáticos y siempre pueden re-interpretarse, re-visitarse, re-significarse. Es el arte de componer, con mayor o menor dramatismo, un lugar - en apariencia- apartado del mundo que, en su atmósfera de enseñanza, convida a un aire indispensablemente libre. Ambiente libre de juicio; podría decir un cartel: «prohibido juzgar». Esto molesta un poco a las oligarquías de la técnica y a la nueva burguesía de la tecnología, pues en su selecto club se admiten a quienes saben mirar por encima del hombro y escupir sobre las anacrónicas ideas que todavía pueden decirnos algo fuera de los «ambientes de aprendizaje».

Es la educación pública la que late bajo estas pieles de reflexión, la que, aun con todas sus falencias e imposibilidades, necesitamos defender ante los ataques del mercado en sus variantes emocionales, cognitivas, tecno-evaluativas. Es la tierra donde los recursos son escasos, donde puede alimentarse la prosa singular del mundo que hace lugar a muchos mundos y que algún día alguien podrá degustar o darle vueltas con una cuchara sopera. Una chance de hacer la vida menos miserable en su existencia, de no reducirla al número que hace bulto en la estadística o al gesto inenarrable que no tiene gracia. Otra manera de evitar convertirnos en el pedestal pasivo sobre el que se asienta la gran civilización creyendo que nos fecunda con su pipí, y no solo pensar en nuestro pan, sino en la igualdad que alimenta las ganas de vivir, la paz popular que se nutre de los combates y la libertad comunal que esquiva la jerarquía militar. 
No son meros tópicos de conversación, ni poses para llenar un vacío o matar el tiempo haciendo un monólogo singular que demuestre algo a alguien. Podríamos evocar a Meckert y decir que educar también se trata de hacer verdadera política: discutir conjeturas imposibles, indignarse ante las desigualdades, sin perder la alegría, nunca satisfechos, confundirse en el deseo, hallar en el bolsillo otra ignorancia y sentir una fragilidad tal que un sofisma en plena cara nos puede noquear. No es que se piense mediante consignas, sino que se habita una verdad que no deja firmeza en la opinión y que pide escudos desde los cuales "plantarnos detrás de las piedras y las inmundicias, [obligados] a buscar la placa blindada, sólida y resonante, que vibra cuando recibe metralla" (Meckert 134). Arriesgamos la vida en algunas querencias...

Se dice que quien «no tiene» palabras con las que defenderse recurre al ruido o a los golpes. Lo intraducible, que no es lo insignificante, tiene su fuerza y su comedia. La tragedia no llega a verse en la impuntualidad de la cita; a lo mejor puede escucharse en la ausencia de una voz cuyas cuerdas ya no vibran.

No se miden los golpes, no importa si son de efecto o de afecto, pero pesan como el ruido ínfimo en el silencio de una siesta. Así es que la irritabilidad masculla zonceras y se inflama ante el error inevitable. Con frecuencia se olvida lo errática que es la vida: un combate por sostener el bombeo político del deseo.

Poetas en la infancia del mundo llegan a glorificar una cáscara de nuez, luego de saborear su fruto celebrado y devorarse sus sesos, puede percibirse un resto a pensar. Y si las palabras se hacen artificio, otra lucha contra la impostura se dibuja.

Y no será en círculo el dibujo porque de esos símbolos viciosos están hechas las historias, como la que narra la vivencia de un joven que desea a una mujer violentada por su pareja y que después él mismo se transformará en otra pareja capaz de disfrazar una escena de violencia como una avería que justifique su llegada tarde al trabajo y haber perdido nada más que una hora.

Educación, enseñanza y literatura podrían ser tridente de liberación o al menos el ménageà-trois que le dé otra entonación a la vida. Pero no habría que descuidar la "y» que articula. amor no es el "Uno» que todo lo puede, menos el dos que se acobija en su estufa dualista, tampoco el tres que se dirime entre el secreto y la síntesis, ¿o acaso será el arrebatado cuatro que junta las anterioridades comunales y las pone a bailar en múltiples combinaciones? 


\section{El pensamiento contrafactual como ejercicio educativo-literario de resistencia}

Cuando Hebe Uhart intentó pensar la epojé a su modo, creó aquel simpático neologismo, "desfulanizar», con el que pretendió referirse a cierta capacidad de aproximarse al conocimiento de los otros intentando prescindir de todo aquello que les rodea y constituye (como la familia, el trabajo, los quehaceres cotidianos). Su propuesta parece insinuar un intento de desconectar a la gente de ciertas marcaciones que intentan entenderla y explicarla (sin ir más allá de esas relaciones establecidas). Una suerte de gesto que permite lanzarnos a otra forma de estar en el mundo, quizás inédita.

Desfulanizar como dar lugar al desvío por procurar una re-significación, cual arte de producir una des-marcación de lo que se sabe de alguien y -podríamos agregar también- de lo que se sabe sobre un concepto, sobre una cuestión particular o sobre un hecho histórico, propiciando la ruptura respecto a la consideración o tradición en la que anida y de la que parece no poder sustraerse a la hora de comprenderse. $Y$ este arte o actividad dista de la deshistorización o idealización. Por el contrario, no se trata de quitar el contexto por ir en búsqueda de esencias o verdades originarias; se trata de abrir la perspectiva de alguien o algo hacia una zona en la que se pueda atender a otras opciones de sentido que inquieten, pongan en movimiento o ataquen de algún modo la estaticidad de las percepciones acomodadas.

Desfulanizar se manifiesta, entonces, como la potencia de jugar a desconocer o a barajar de nuevo e imaginar una nueva historia por narrar, aunque también podría presentarse como vocación lúdica de esa impotencia que impide a una totalidad seguir siendo del mismo modo. Como un cuento que empieza a balbucearse esbozando alternativas para lo que fue, para lo que está siendo y lo que podría ser. Tal vez como sucede en el pensar contrafáctico, a través del que se pueden imaginar variantes para lo acontecido en un pasado, conjeturando diversos aspectos y consecuencias diferentes para ciertos sucesos.

En general, la conjetura imposible o el contrafáctico son modos de ejercitar el pensamiento que no ha gozado de muy buena fama al interior de varias disciplinas. Quizá por haber sido juzgadas entre las tareas intelectuales más infructuosas y vacuas a las que alguien pueda entregarse. El contrafáctico se define como "un enunciado condicional, contrario a los hechos acaecidos; algo incumplido, un condicional cuyo antecedente no se cumplió o no se cumple" (Levinas 25), y que puede ser no solamente una herramienta para analizar la historia, 
sino también una práctica educativa-literaria que favorezca una deconstrucción con vistas a un presente y un futuro diferentes. Dicha visión puede resultar fundamental para abrir lo imposible, para cuestionar lo sucedido y -sobre todo- para avizorar otras visiones de futuro.

En resumen, conjeturar lo imposible y ejercitar el pensamiento contrafactual sería un arte al servicio de la resistencia y la liberación respecto de las formas opresivas de concebir y estar en el pasado y en el presente, permitiendo situarnos en perspectivas otras mediante la recreación de tiempos alternativos (como, por ejemplo, en la ucronía, ese tiempo en el que se invita a imaginar una historia distinta respecto a la sucedida). Una historia imaginada en la que vida y literatura se entrecruzan y facilitan la entrada a la crítica y reversión de una realidad (y de las conceptualizaciones que se han vuelto parte de un lenguaje impostado) ante la perspectiva de un horizonte heterogéneo.

La ucronía es aquello que no se halla en ningún tiempo, pero que paradójicamente se vincula con algo que aconteció y que no puede ser ubicado en una cronología precisa. No es algo totalmente inventado, sino desviado de su curso efectivo, tal y como sucede con los enunciados contrafácticos. Tanto en la ucronía como en los contrafácticos se piensa en hechos no transcurridos, pero que hubiesen podido acontecer. La ucronía es el relato de lo que "hubiese pasado si..." y el por qué no de "lo que pasaría si..." (Levinas 126).

En este sentido, la evocación de la ucronía o del pensar conjetural y contrafactual se tornan ejercicios que pueden conducir a un tipo de enseñanza crítica, creativa y emancipatoria. Y desde ahí regar la tierra del ensayo como intento de una educación que convoque (y provoque) significaciones pasibles de volver a cuestionarse una y otra vez en el marco pedagógico de esas enseñanzas que habilitan espacios conversacionales de los tiempos que vienen y van repitiendo los síntomas ignorados de sus historias. Tiempos próximos en los que las relecturas pueden necesitar de rescates que abran generosamente las páginas sobre las que alguna vez se encerró algún sentido, el cual, por una pulsión de conversación, se llega a reabrir, con un tacto capaz de hacer temblar la hoja reseca por el paso del tiempo y humedecer la tinta seca de antiguas letras que interrogan el presente desde otra época, no para reimprimirlas simplemente, sino por re-vivirlas desde otras vidas y otras formas.

Puede que la primera objeción al pensamiento contrafáctico venga por el lado de la clásica acusación de improductividad, porque conjeturar a ese nivel sería una pérdida de tiempo, porque no cambiará la historia pasada o porque de nada servirá en el tiempo presente. Sin embargo, 
la potencia (e impotencia) de embarcarse en este tipo de ejercicios es la de aventurarse a dejar latir otras percepciones que naveguen en búsqueda de lo no sabido, aquello que no se deja comprender del todo, pero que figura en las cercanías de lo que se juega. Además, desde una concepción de la enseñanza (o del aprendizaje) que cuide la incógnita de una inteligencia vinculada al deseo, en su manifestación literaria como forma de resistencia a ese tipo de lenguaje funcional de la productividad mercantil, aquellas objeciones no amedrentan ni damnifican. Será porque una educación (literaria, conjetural, contrafáctica) avocada a generar espacios y tiempos en los que repensar conceptos o momentos históricos, y asimismo imaginar otros presentes (planteados a veces como imposibles), incluso en sus resquicios enigmáticos, se manifiesta como una forma de mantener viva la fuerza emancipatoria de soñar (y hacer) una realidad diferente.

\section{En la selva de la literatura: ¿una enseñanza de escape y superstición?}

En la historia latinoamericana, la selva ha sido siempre un buen lugar de refugio para quienes escapan o para quienes combaten. Quien hace de la selva su casa no queda exento de esa suerte. Tal vez escapa del tiempo previo y deja allí librada la vida de toda justicia, pese a la supuesta tiranía que se le suele adjudicar a su ingobernable dinámica o a la benévola creencia de una sabiduría natural que atraviesa todos los órdenes. En tal escenario, un escritor, al tiempo que mandaba los manuscritos a alguna que otra editorial, se aventuraba en lo urgente sin vida por ganar, más bien, al paso que se daba algo de ella, podía o no alterarse, dependiendo de dónde se haya puesto el pie.

Las escrituras de Horacio Quiroga no son de un camino seguro, brotan impredecibles como la flora y la fauna en quien las lea y se interne en ellas, poco a poco, como un invasor que al cabo de un tiempo termina siendo absorbido hasta puntos inimaginables por la espesa y desconocida selva. De cualquier modo, quien entra a la selva, como Horacio nos lleva a hacerlo, no cobra nunca pertenencia ni conocimiento de lo que hay allí dentro. En esta aventura llegamos a percibir figuras que, interpretativa y entreveradamente, pueden alojar una huella educativa escondida tras la forma de cuentos alucinados. Así, una de ellas podría ser la literatura 
como una selva, la segunda es el escape (de la subjetividad que venía siendo) y, por último, la superstición como susurro de lo improbable.

Si uno piensa la obra y biografía de Horacio Quiroga, escritura y selva, más que una metáfora, podría funcionar como una relación que está siempre latente. No obstante, sospechamos que no solo es importante en tanto relación. Llevarla al campo de la metáfora también nos permite pensar maneras de proyectarla a la educación. Ya que es vasto, en literatura, pensar figuras que han ido de la escritura a grandes nociones de análisis (un ejemplo podría ser la del desierto), aquí la idea de la selva podría cobrar ese estatuto sin quedar mediada por una idea manipulable de conocimiento. Al contrario, Quiroga nos muestra que se trata de un lugar que toma como parte de sí a los personajes hasta dejarlos sujetos a una realidad que está por verse, donde algo de lo dado se suspende.

En tal sentido, la literatura como selva nos permite pensar por fuera de lo que puede ser objeto de una campaña de conquista o de un plan para atravesarla, precisamente porque estas simples operaciones están impedidas. E incluso lo mismo podríamos suponer de otras acciones que están más instauradas en relación con la selva (como la de inspeccionar, penetrar, internarse, dominar o el acto mismo de señalar). Todas ellas, envueltas en lo selvático, podrían transformarse en un falso espejismo del hombre consciente y racional. Entonces, ¿qué potencias e impotencias de enseñanza habitan en la literatura como selva?, ¿de qué actos está compuesta?, ¿puede pensarse una educación a partir de ella?

Invirtiendo la monotonía del desierto y centrándonos en la tumultuosa vida selvática, el autor nos lleva a introducir una necesaria dimensión estética-cinematográfica que permite hacernos parte de las imágenes en sus movimientos y en sus cambios imperceptibles. Un ejercicio u operación de tomas y escenas hechas con imágenes jamás captadas, que cobran sentido en la continuidad del relato y en el cuidadoso trabajo de montaje. Puede que esta literatura (y su huella educativa) habilite el juego de una lectura que pueda escapar a nuestra comprensión y entendimiento, tras entregar parte de nosotros a esos trazos que, al mirar para atrás, ya han cambiado.

Distinto es pensar en los aprendizajes controlados, aciertos interpretativos de una gramática técnica exenta de error. En la selva, como en los cuentos, es poco lo que se sabe y la escritura se torna mística y subrepticia, desaparece al tiempo que nos va dejando estar cada vez más dentro de sus escenas. Esto nos lleva a imaginar una enseñanza, no como un camino 
trazado que se recorre con más o menos obstáculos, sino como un sendero frondoso que tiende a desaparecer al paso de quien se va moviendo y ofrece un lugar distinto que ya no ha de poder ser punto de comparación con el anterior: un lugar que tiene ya al sujeto como parte de su espesura.

Otra figura que se aparece, al pensar la escritura de Quiroga, es la del escape. En sus cuentos, los personajes suspenden su conciencia y capacidad de control a medida que se van entrometiendo en la selva. Comienzan a cambiar los motivos que los habían llevado a permanecer un tiempo allí y, del mismo modo, cambia el parecer respecto al lugar en el cual están. Lo que allí comienza a suceder cobra sentido al tiempo que el personaje se encuentra envuelto en una situación completamente insólita, hasta formar parte del follaje selvático y entregar los privilegios que lo nombraron y le dieron origen alguna vez. Exentos de la razón que hasta entonces parecía dirigir sus vidas, los personajes comienzan a narrar la vivencia. En este plano, la figura del escape está presente en tanto entrada (o entrega) a un lugar incondicionado.

Tal vez esta paradoja marque una insinuación vivaz de la escritura que allí se trama: una literatura que permite un desacuerdo con lo que venía dado subjetivamente y que obliga a desencadenar una historia sin más recompensa que la chance de escapar. ¿Acaso no sucede algo similar con una educación liberadora que da la bienvenida a cualquiera que en su accionar fugitivo intenta resistir alguna forma de opresión? A lo mejor así se trama una formación emancipatoria, un lugar sin condición al cual podemos escapar.

La última figura, junto a las dos ya mencionadas, coincide en la idea de que no se trata de una ley de la selva (la cual supone una supervivencia a costa de todo o la preponderancia de las mejores aptitudes y fortalezas). Por ello, entra en escena la superstición como un elemento fundamental, en tanto permite situar la existencia sin aportar prueba alguna. Aparece como única guía del relato, una vez que algún personaje vuelve del estado catatónico. Comedidamente, el mito o la leyenda aparecen en la narrativa para dar lugar a lo que ha sucedido sin necesidad de abandonar del todo esa vivencia. Esta figura permite pensar un pasaje diferente, tal vez el de una literatura que no parte de una supuesta individualidad a una traducción colectiva -como se suele considerar-, más bien sería un juego en donde se confirma la experiencia colectiva a partir de la ruptura -común y silvestre- con las condiciones privilegiadas del individualismo que la caracterizaba. En estos mismos términos, corresponde 
situar a la enseñanza como lugar de experiencia que no ha de poder ser comprobada, pero tal vez oída por una pedagogía que permita sentarse (incluida ella misma) a escuchar un relato que comience con un "yo nunca..., pero que las hay, las hay".

Después de todo, si atendemos las insinuaciones de Alfonsina Storni, Quiroga es un artista-docente que en un drama "indiferente o sin relieve para la mayoría, capta el rasgo extraordinario y sabe presentarlo a los demás de manera que comprendan lo excepcional" (333).

\section{Pronunciaciones: poética, deseo y cuidado}

Plegaria para un niño dormido quizás tenga flores en su ombligo

déjenlo que siga soñando felicidad destruyendo trapos de lustrar (...) jugueteando inquieto en los jardines que jamás despierto encontrará.

Luis Alberto Spinetta

Quizás uno de los gestos más generosos de la literatura sea el de abrir la poesía al mundo. O más bien, el de confirmar la sospecha de que la poesía, más que un género, es un fenómeno que sopla por doquier, muy a pesar de la rima y de la métrica. Es ese gesto que permite pensar que lo poético puede estar en la contemplación de un paisaje, en el sabor del chocolate, en el silencio de la noche.

Mostrar el nudo deshecho entre la poesía ${ }^{4}$ y el poema fue una de las pronunciaciones de Octavio Paz, quien pensó a la primera como una especie de fuerza no apresable entre las reglas del poema. Una fuerza que es una vivencia humana capaz de experimentarse entre variadas formas y sensaciones. En cambio, el poema no. El poema puede ser de métrica y rima perfectas, respetar la técnica y lograrse como obra literaria, pero no necesariamente como experiencia poética. La poesía es la idea de lo que trasciende al elemento. Es aquello que se despega de las coordenadas de una clase de obra en particular e incluso de un arte en especial. Toma vida propia. Una vida que siempre es un más allá, inasible, y, por esto mismo, un quehacer que ha

\footnotetext{
${ }^{4}$ O lo poético. Los utilizaremos como sinónimos en este caso.
} 
parecido esconderse y manifestarse; desaparecer y retornar como musa, como revelación, como deseo.

Octavio Paz publica El arco y la lira en 1956, obra en la que recorre distintas visiones sobre la creación poética: desde la antigua noción de inspiración como posesión hasta la idea surrealista de inspiración como fuerza creadora e involuntaria ${ }^{5}$. Y es en ese trayecto que se acerca a la idea de que la producción poética es un hacer, es una actividad que no está en ninguna parte, en ningún lugar ni disciplina precisa que se pueda indagar, sino que es un desplazarse, un ir de camino. Pero en todo caso siempre guarda la nota de ser una búsqueda intencionada, una decisión hecha desde la propia libertad, desde el deseo de interrogar a esa voz extraña que suelen describir los poetas. Es un querer acceder a ese llamado que es la poesía. Quizás una mezcla de voluntad de ir y las ansias de ser llevado hacia...

¿Un deseo de vida poética será lo que impulsa? ¿Un poder mantenerse en ese andar será lo que sostiene? ¿Cómo cuidar esa búsqueda? Y también: ¿Cómo acompañar ese camino en el que otros se aventuran? Así se deja pensar ese cuidado del sueño del otro a través de la Plegaria para un niño dormido, en la que pareciera augurarse un porvenir lírico para aquel niño envuelto en sueños y letras reunidas que convocan la pronunciación hacia el abrigo de esa existencia. Mas, ¿cómo estar al resguardo de ese impulso que late?

Según puede verse en la escritura de Octavio Paz, lo poético se construye (o se cuida, podríamos agregar siguiendo el trazo anterior) en la búsqueda de cierta intimidad. Se da en la disponibilidad hacia la exploración de un universo interior que interpela, que llama, y que no es sino parte de una voz propia y ajena a la vez; un llamado que parte de la voz interna, que es la voz del mundo y que es el lenguaje de los otros también. En ese viaje a una interioridad no solipsista -que manifiesta el lazo cuasi indiscernible entre el yo y los otros- es que se despliega esta clase de creación. Y este encuentro revela las claves fundamentales de nuestra existencia

\footnotetext{
${ }^{5}$ Mientras que en la antigüedad griega la inspiración era concebida como delirio o posesión, o como una manifestación de la divinidad, para los modernos esa "voz ajena" se vuelve un problema porque no es pasible de ser adaptada a sus concepciones intelectuales del mundo. Intentarán, entonces, negar esta voz, vincularla a una imagen retórica, luego a la idea de pereza intelectual. Por tanto, ese desdoblamiento del acto poético, ese elemento extraño que aparece llamando al poeta, se resiste a ser explicado por las mentes modernas, pues implica una amenaza para la identidad de la conciencia. Serán los surrealistas quienes intentarán desmarcar los límites que durante siglos hizo de la inspiración un fenómeno extraño al mundo. Estos pensadores pretendieron desdibujar la estructura sujeto-objeto explicando la creación poética como una suerte de fuerza creadora, involuntaria, que niega al sujeto (que se disuelve) para acceder a la inspiración.
} 
como un despegue constante hacia la fecundación de sentidos y la comedia de lo que se está siendo. Una existencia que consistiría en pronunciar de otra manera esas palabras del mundo que forman parte de aquella intimidad. Palabras que vienen de los otros, sonidos extraños y familiares en lo éxtimo. Despertares a la condición de crear que se hace manifiesta. Crear como nacer y como apalabrar. Un encuentro con la forma vital de re-versionar lo humano que nos habita.

Octavio Paz nos ayuda a pensar en ese cuidado a partir de la idea del encuentro con la capacidad de crear que se hace -o se oye- en lo íntimo de la escucha. Una capacidad que es una experiencia en y desde el lenguaje, pero que no se aprisiona en una sola forma de comunicar, sino que también puede adquirir otras configuraciones, logrando ser parte de diversos modos de expresión. Así, la experiencia poética, aunque siempre es un más allá que puede depender de fenómenos que exceden a nuestra voluntad y presentarse como una vivencia abismal y estremecedora, se da en una forma próxima a través de distintas gestualidades.

Cuidar las existencias poéticas desde un ámbito educativo no sería más que velar -como en el sueño del niño- y acompañar, quizá sigilosamente, el deseo inventor de quienes comienzan una travesía. Velar como estar en la vigilia y a la espera de las palabras y los gestos que llegan como indicios de diversas búsquedas. Aventuras que se traducirán en una ética liberadora y en el arte de crear sentidos singulares, es decir, de mentarlos, de explorarlos, de intuirlos, de compartirlos o, incluso, de reinventarlos. En suma, cierta manera de jugar con una arcilla incierta que toma alguna forma y que un/a poeta significa.

\section{Telón: el estudiar, ¿arte de lucha 0 artificio de supervivencia?}

Una madre ahorra vueltos con los que luego intentará procurar todo lo necesario para enviar a su hijito a la escuela. Todo a escondidas, claro, porque el padre es bastante terco y no entiende para qué el niño iría a la escuela cuando puede vender diarios o hacer algunos trabajitos que colaboren con los ingresos de la economía familiar. No importa, la madre se las ingenia y el niño asiste al turno de noche escapándose bien vestido por el zaguán. Esto podría evocar la idea de "ganar la noche» que los obreros practicaban cuando se juntaban a leer y se formaban al calor de las velas y los libros que oficiaban de interruptores del ciclo embrutecedor que los llevaba del trabajo a la casa y de la casa al trabajo, cual rehenes del tiempo devorador que solo 
empuja a comer, descansar y repetir la rutina cada día sin horizontes de liberación. Por eso fue necesario interrumpir el ciclo, arrebatarle tiempo a la rutina mortificante y llevarlo a un horizonte vital de formación que pudiera perfilar las luchas necesarias por otros modos de vida alejados lo más que se pueda de las dinámicas de explotación.

La narración ampliada de la pequeña historia que abre este pasaje puede encontrarse en una impresionante novela argentina de finales del siglo XIX, escrita por Eugenio Cambaceres. Su título, En la sangre, emparentado con cierto argumento naturalista, lejos está de las insinuaciones éticas y políticas que aloja, las disrupciones de lenguaje que provoca y la generosidad de su imaginación crítica, que la convierte en una obra fundamental de la relación amorosa (y por eso filosófica) entre literatura y educación. De aquí que no sea un dato menor el hecho de que la primera situación de examen que se narra en la novela involucre a un cadáver que es visto desde lejos y solo un instante baste para que el muerto examinado se transforme en un informe.

En esta suerte de cadena significante, el siguiente eslabón se encuentra en la duda sobre la veracidad del catecismo que señala el día del juicio como momento de resurrección y algunas páginas más tarde encontraremos a un profesor comentando la habitualidad de que un/a joven, antes que sea admitido en un colegio, sufra un examen de gramática que determina la posibilidad o no de matriculación. Como si el juicio traducido en examen permitiera otra forma de resurrección: la curiosidad inconsciente de la infancia debe, si quiere obtener su existencia «estudiantil», rendir cuentas y alegar en función del requerimiento de turno. De lo contrario, se perfilaba una nota de infamia que amarga el corazón, lo llena de despecho y oscurece el porvenir con su cuota de humillación y vergüenza en un presente que amenaza con hacerse continuo.

Es interesante que, renglón seguido, Cambaceres marque el inicio de una vida de lucha cuando el personaje de su narración se consagra de lleno al estudio, con pasión y un anhelo constante de saber, un afán que le hacía redoblar su dedicación y ahínco. La relación vida de lucha-estudio rápidamente se traduce en la de sacrificio-valor, pues aparece la pregunta por el premio, la recompensa, la ganancia y la identidad directamente vinculada a su sacrificio, a su matarse estudiando, a su devanarse los sesos. Nada de lo cual pareciera bastar para quitarse de encima pesados adjetivos que describen su espíritu como vulgar, su condición de estudiante como ramplón y adocenado, o peor: "esos que bajo la capa artificiosa del estudio, disimulan su indigencia intelectual; plantas que se arrastran por el suelo sin lograr clavar sus raíces, vegetan 
y se secan sin dar fruto", que es una condena al doloroso viacrucis en el que se hace todo para merecer "la deprimente limosna de un título usurpado de suficiencia" (Cambaceres 75). El estudio como artificio y recurso de disimulación, la vida estudiantil rebajada al estado vegetativo que no prende en el suelo y se va secando mientras la condena lleva al examen que obliga a confesar la impotencia o a asumir el sordo malestar con tal de intentar esquivar un desempeño vergonzante y llegar...

Llegar a calificar bien o, lo que es lo mismo, a desarrollar el talento de engañar a los otros haciéndoles creer que se sabe lo que se espera que se sepa para tal o cual instancia. Talento para la apariencia, talento para el disimulo, talante para el engaño. Este artificio del estudio, tan alejado del arte de estudiar, se impone como la insalvable valla de lo imposible que impone el uso de máscaras y no para jugar con la seducción del secreto, sino para eludir la angustia de quien se ve rodar al fondo de un abismo. Es que en estas partidas se juega el todo por el todo, las cuestiones parecen de vida o muerte y un resultado adverso, un fracaso posible, puede significar el desvanecimiento de una esperanza para siempre. Esto más allá y más acá del rechazo o la reprobación desdorosa que pueden coartar una lucha. Así, las dificultades de comprensión, o la propia ofuscación, pueden producir un interminable laberinto en la cabeza en el que terminamos perdidos y sin salida. Sin descuidar el aguijón del miedo que comienza a hostigar, mientras se intuye un mal que podría resultar o un daño por elaborar, cuando el aparato de suplicio se acerca y el lugar de examinado se torna real: banquillo acusatorio a mano, culpable hasta que demuestre lo contrario.

Y, si de demostrar se trata, ¿qué sucede si se toma un atajo por evitar también esa muerte simbólica más cruel y mil veces más infamante que otras? Esta pregunta ética se insinúa entre las líneas de Cambaceres cuando su personaje desliza la chance de asegurarse un resultado "exitoso», un sobresaliente conquistado o una mención honrosa en la mesa que garantice una victoria en la contienda a base de una travesura, una cábula de estudiante con el fin de sacarse la soga del cuello y pasar el mal trago. Pero el interrogante moral se explicita sobre la especulación de ese primer paso que podría ser el comienzo de una escalada de abyección conducida por la pendiente resbaladiza de la culpa y un problema ético-político se perfila en el planteo de Cambaceres que sumerge a su personaje "en tiempos en que el éxito primaba sobre todo, en que todo lo legalizaba el resultado" (83). 
De cualquier modo, todo se reduce a un manejo ineludiblemente impostado: guardar las formas, cubrirse, tener garantía y vender el oropel del saber con destreza teatral a fin de conseguir alguna apoteosis, independientemente de qué tan artificial se torne el vivir. Solo importa sacar el clavo, esquivar la nube negra y luego, una vez realizado, ir por más como si otro mundo color de rosa empezara; pero la gente empeñada en sus rendimientos difícilmente pueda ver algún color porque nada miran en la indolente realidad de su progresión. Amanuenses, lejos están de los trazos de hacha y tiza que no tienen fecha de vencimiento, las reminiscencias del examen retornan en pesadillas e instancias de vida: escuchan el ruido de la comisión evaluadora, ven en todas partes los formulismos secretos del tribunal.

Simuladores de talentos, Cambaceres nos enseña desde el siglo XIX que el gran pasador de exámenes (más allá de los medios que emplee para ello) se emparenta con el impostor que conquista mostrándose fino y elegante, amable y envolvente, engatusador e hipócrita, hasta que alguien aprende de sus embustes y artificios. Es entonces cuando ese tipo de racionalidad intenta mejorarse a sí misma, en su performance nutrida de farsas y cinismos, o un jaque mate la arrincona frente a una espada-pregunta de imposible solución...

¿Será por avistar rayana esa espada y andar cerca de la pared que suele aplazarse la relación amorosa -y por ello filosófica- entre educación y literatura? ¿O es que se teme a lo in-evaluable ${ }^{6}$ de una enseñanza literaria que no se deja medir, no se deja atrapar en la tasación y se escapa de cualquier impostación?

Tocata y fuga suena en el saber que no se sabe, mientras la verdad -siempre a medio decir- siembra el enigma fundamental que queda picando en la relación amorosa y mantiene con vida el misterio del día.

\footnotetext{
${ }^{6}$ Lo in-evaluable se caracteriza por lo imposible, que no quiere decir irrealizable, aunque involucre cierta insuficiencia en el resultado, e implica al deseo y la palabra como singularidades irreductibles que constituyen una curvatura que se resiste a cualquier procedimiento de enderezamiento (Giuliano, Psicoanálisis y educación).
} 


\section{Referencias}

Andruetto, María Teresa. Lengua madre. Buenos Aires: Mondadori, 2010. Impreso.

Borges, Jorge Luis. Obras Completas 1923-1972. Buenos Aires: Emecé, 1974. Impreso.

Cambaceres, Eugenio. En la sangre. Buenos Aires: Colihue, 2006 [1887]. Impreso.

Giuliano, Facundo. "Infancia y razón evaluadora: contrariedades y resistencias pedagógicas (entre filosofía y literatura)". Enunciación. 25.2. 2020: 220-231. Digital.

Giuliano, Facundo. "Psicoanálisis y educación: acerca de lo imposible versus la razón evaluadora". ECOS-Estudos Contemporâneos da Subjetividade 10.1 (2020): 123-144. Digital.

Giuliano, Facundo. "Razón evaluadora y escenarios del juicio educativo". Pensamiento Actual. 20.34. 2020: 74-90. Digital.

Henríquez Ureña, Pedro. "La enseñanza literaria en la escuela". El Monitor de la Educación Común. 53.731. 1933: 3-12. Impreso.

Levinas, Marcelo Leonardo. La naturaleza del tiempo. Usos y representaciones del tiempo en la historia. Buenos Aires: Biblos, 2008. Impreso.

Meckert, Jean. Los golpes. Barcelona: las afueras, 2017. Impreso.

Paz, Octavio. El arco y la lira. México: Fondo de Cultura Económica, 1967. Impreso.

Quiroga, Horacio. Cuentos de la selva. Buenos Aires: Losada, 1978. Impreso.

Rodó, José Enrique. El mirador de próspero. Montevideo: Librería Cervantes, 1913. Impreso.

Sloterdijk, Peter. Normas para el parque humano. Madrid: Siruela, 2006. Impreso.

Storni, Alfonsina. Escritos: imágenes de género. Villa María: Eduvim, 2014. Impreso.

Uhart, Hebe. Un día cualquiera. Buenos Aires: Alfaguara, 2013. Impreso. 